\title{
The solar activity dependence of nonmigrating tides in electron density at low and middle latitudes observed by CHAMP and GRACE
}

\author{
Yun-Liang Zhou ${ }^{1,2}$, Li Wang ${ }^{1}$, Chao Xiong ${ }^{2,1}$, Hermann Lühr ${ }^{2,1}$, and Shu-Ying Ma ${ }^{1}$ \\ ${ }^{1}$ Department of Space Physics, School of Electronic Information, Wuhan University, 430072 Wuhan, China \\ ${ }^{2}$ Helmholtz Centre Potsdam, GFZ German Research Centre for Geosciences, Telegrafenberg, 14473 Potsdam, Germany
}

Correspondence to: Yun-Liang Zhou (zhouyl@whu.edu.cn)

Received: 9 October 2015 - Accepted: 12 April 2016 - Published: 27 April 2016

\begin{abstract}
In this paper we use more than a decade of in situ electron density observations from CHAMP and GRACE satellites to investigate the solar activity dependence of nonmigrating tides at both low and middle latitudes. The results indicate that the longitudinal patterns of $\mathrm{F}$ region electron density vary with season and latitude, which are exhibiting a wavenumber 4 (WN4) pattern around September equinox at low latitudes and WN1/WN2 patterns during local summer at the southern/northern middle latitudes. These wave patterns in the $\mathrm{F}$ region ionosphere can clearly be seen during both solar maximum and minimum years. At low latitudes the absolute amplitudes of DE3 (contributing to the WN4 pattern) are found to be highly related to the solar activity, showing larger amplitudes during solar maximum years. Similarly a solar activity dependence can also be found for the absolute amplitudes of D0, DW2 and DE1 (contributing to the WN1 and WN2 pattern) at middle latitudes. The relative amplitudes (normalized by the zonal mean) of these nonmigrating tides at both low and middle altitudes show little dependence on solar activity. We further found a clear modulation by the quasi-biennial oscillation (QBO) of the relative DE3 amplitudes in both satellite observations, which is consistent with the QBO dependence as reported for the E region temperatures and zonal wind. It also supports the strong coupling of the low-latitude nonmigrating tidal activity between the $\mathrm{E}$ and $\mathrm{F}$ regions. However, the QBO dependence cannot be found for the relative amplitudes of the nonmigrating tides at middle latitudes, which implies that these tides are generated in situ at $\mathrm{F}$ region altitudes.
\end{abstract}

Keywords. Ionosphere (equatorial ionosphere; ionosphereatmosphere interactions; mid-latitude ionosphere)

\section{Introduction}

The ionosphere-thermosphere (IT) system is a crucial part of the solar-terrestrial interaction region and is an important research objective for space weather. It is well known that the IT system varies noticeably with different spatial and temporal scales. This variation is caused not only by the effect of solar radiation, interplanetary, magnetospheric processes, but also by the waves propagating up from the lower atmosphere. The combined effects of the aforementioned various driving mechanisms determine the changes of composition, temperature and density of the ionized and neutral constituents in the IT system (Schunk and Sojka, 1996).

In the past decade much effort has been devoted to investigating the longitudinal variations of the ionospheric and thermospheric quantities, which are often related to lower atmospheric processes, especially to the influence of various waves. These waves are referred to as atmospheric migrating and nonmigrating tides with periods that are harmonics of a solar day (Forbes, 1995). The migrating tides are mainly generated in the troposphere and stratosphere through the absorption of solar energy by tropospheric water vapor and stratospheric ozone (Oberheide et al., 2002). From the perspective of a ground-based observer they propagate westward with the motion of the Sun and thus will not cause a longitude variability at a fixed local time around a constant latitude circle. The nonmigrating tides do not migrate with the Sun. Therefore they will cause longitudinal variations of the IT system if viewed at a fixed local time. According to previous studies nonmigrating tides are mainly excited by zonal asymmetries of driving mechanisms (e.g. topography, land-sea differences, longitude dependence of absorb- 
ing species) (Forbes et al., 2003), or by nonlinear interactions between the migrating diurnal tide and planetary waves (Hagan and Roble, 2001), or gravity waves (McLandress and Ward, 1994), or by the latent heat release in the troposphere (Hagan and Forbes, 2002).

In the universal time (UT) frame, these tides can be expressed as (Forbes et al., 2006)

$A_{n, s} \cos \left(n \Omega t+s \lambda-\phi_{n, s}\right)$,

where $t$ is the universal time, $\Omega$ is the rotation rate of the Earth $(\Omega=2 \pi / 24 \mathrm{~h}), \lambda$ is the longitude, $n(n=1,2,3, \ldots)$ is the harmonic of a solar day, $s(s=\ldots-3,-2,-1,0,1,2$, $3 \ldots)$ is the zonal wave number, $A_{n, s}$ is the amplitude, $\phi_{n, s}$ is the phase of the tides and defined as the time when the maximum passes the zero degree longitude.

When viewed in the local time frame, Eq. (1) becomes

$A_{n, s} \cos \left(n \Omega t_{\mathrm{LT}}+(s-n) \lambda-\phi_{n, s}\right)$,

where $t_{\mathrm{LT}}\left(t_{\mathrm{LT}}=t+\lambda / \Omega\right)$ is local time. When $s=n$, the components denote migrating tides and are longitude independent. While when $s \neq n$, the components represent nonmigrating tides, with wave number $|s-n|$ observed in longitude for a fixed local time. For labeling the tidal components we use the common convention. The first letter D, S, or T stands for diurnal, semidiurnal or terdiurnal; the second letter $\mathrm{E}$ or $\mathrm{W}$ for eastward or westward propagation and the final number quantifies the azimuthal wave number. D0 represents a wave that is increasing and decreasing simultaneously at all longitudes at a diurnal period. Stationary planetary waves are labeled SPWs and the number at the end quantifies the maxima around the globe. The phase of the SPW defines the longitude where the wave crest occurs. At low and equatorial latitudes the $\mathrm{WN} 4 / \mathrm{WN} 3$ patterns of the ionospheric and thermospheric quantities and the related tidal components have been widely studied (Sagawa et al., 2005; Immel et al., 2006; England et al., 2006, 2010; Lühr et al., 2008, 2012; Kil et al., 2007; Liu et al., 2009; Häusler and Lühr, 2009; Zhang et al., 2010; Xiong and Lühr, 2013; Xiong et al., 2014). These tides originate from the lower atmosphere and can propagate upward to the upper atmosphere, either by direct propagation or through the $\mathrm{E}$ region wind dynamo coupling mechanism (e.g. Wu et al., 2012). At middle latitude Chen et al. (2013) reported an eastward propagating wave 1 pattern of the Weddell Sea Anomaly (WSA) by using the SAMI3 (Sami3 is Also a Model of the Ionosphere) model combined with the Thermosphere-Ionosphere Electrodynamics General Circulation Model (TIEGCM) and the Global-Scale Wave model simulations. Based on the in situ electron density measurements from CHAMP and GRACE satellites, Xiong and Lühr (2014) found a prominent longitudinal WN2 pattern in the northern middle latitudes during local summer. From the global view Xiong et al. (2014) reported the nonmigrating tidal spectrum of the F region electron density in the topside ionosphere for different seasons.
The results showed that at middle latitudes the most prominent tidal components are D0, DW2, SPW1 and DE1. From model simulations Jones Jr. et al. (2013) suggest that at middle latitudes the nonmigrating tides could be generated in situ through ion-neutral interactions due to the longitude dependence of the ionosphere, imposed by the geomagnetic field configuration.

Some recent studies have reported the solar activity dependence of the nonmigrating tides at low latitudes. With 5 years (2007-2011) observations of total electron content (TEC) from COSMIC Chang et al. (2013) reported that the absolute amplitudes of DE3 are directly related to the solar activity, while the relative amplitude (normalized by the zonal mean) is inversely related to the solar activity through 2010 . The solar activity dependence of DE3 has also been checked by S. Wang et al. (2015) by using 14 years of TEC data from global ionosphere maps (GIMs) generated at JPL (Jet Propulsion Laboratory). They found that the absolute amplitudes of DE3 are highly related to the solar activity. However, the relative amplitudes show little dependence on solar activity. CHAMP and GRACE provide more than 10 years in situ electron density $(\mathrm{Ne})$ observations, which offer us a good opportunity for investigating the solar activity dependence of the nonmigrating tides in the topside ionospheric $\mathrm{F}$ region. We will further compare the behavior of tides at low and middle latitudes.

In Sect. 2 we firstly introduce the data sets (ISDC, 2015) and processing approach. Then we will present the observational results from CHAMP and GRACE. The interpretation of the results and the comparison with earlier studies are given in Sect. 4.

\section{Data sets and processing approach}

The CHAMP spacecraft was launched on 15 July 2000 into a near-circular polar orbit (inclination: 87.3) with an initial altitude of $456 \mathrm{~km}$. By the end of the mission, 19 September 2010 , the orbit had decayed to $250 \mathrm{~km}$. The orbital period is about $93 \mathrm{~min}$, thus circling the Earth about 15 times per day. The orbital plane covers all local times within 131 days, at a rate of $1 \mathrm{~h}$ in local time per 11 days (Reigber et al., 2002). The Planar Langmuir Probe (PLP) on board the satellite measured the electron density and temperature every $15 \mathrm{~s}$. The PLP electron density readings have been validated by comparison against digisonde observations at Jicamarca ( $\mathrm{McNa}-$ mara et al., 2007).

GRACE consists of two spacecraft and was launched on 17 March 2002 into a near-circular, polar orbit (inclination: $89.5^{\circ}$ ) with an initial altitude of about $525 \mathrm{~km}$ (Tapley et al., 2004). At the end of 2014 the altitude of the two spacecraft were around $420 \mathrm{~km}$. The local time of the orbital plane precesses by $4.5 \mathrm{~min}$ every day taking the mission 161 days to sample all local times. The two spacecraft follow each other at a distance of about $170-220 \mathrm{~km}$. The total electron content (TEC) between the two spacecraft can be deduced from 


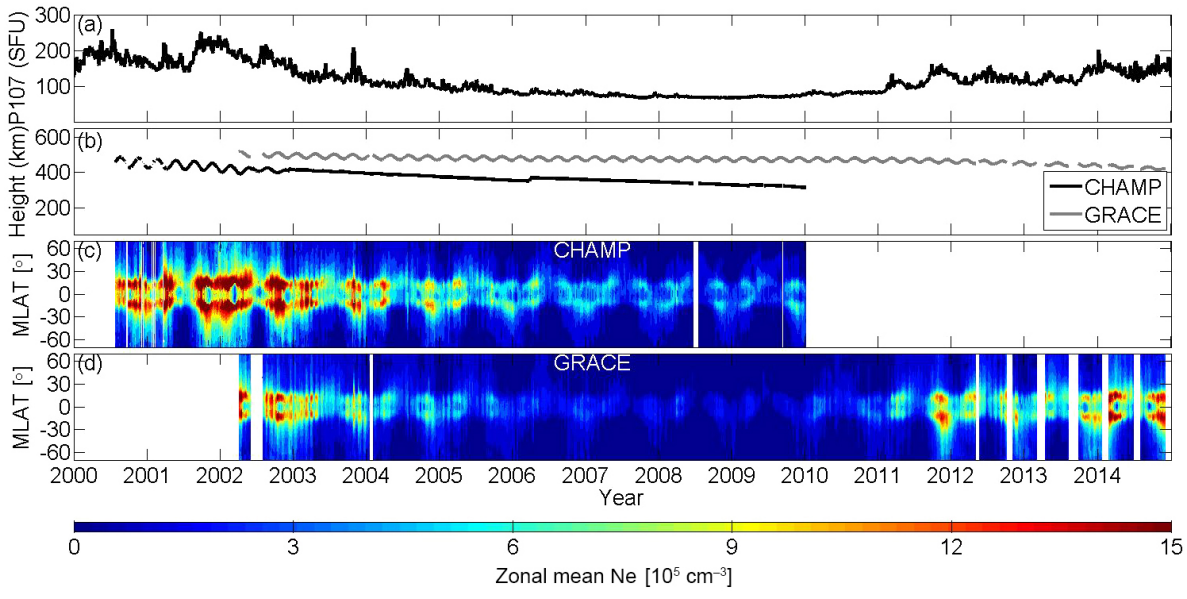

Figure 1. (a) The solar radio flux index P10.7, (b) the ascending node orbital heights of CHAMP and GRACE satellites, as well as the zonal (longitudinally averaged) mean electron density observed by (c) CHAMP and (d) GRACE satellites between $\pm 70^{\circ}$ MLAT from 2000 through 2014.

the K Band Ranging (KBR) data. When dividing the horizontal TEC by the distance between the spacecraft, the averaged electron density can be derived (Xiong et al., 2010; Lühr and Xiong, 2010). The GRACE electron density data are further validated by EISCAT and the Incoherent Scatter Radars (ISR) at Millstone Hill and Arecibo (Xiong et al., 2015a).

As already introduced, the amplitudes of the different tides at the lower atmosphere vary with seasons. The WN4 pattern at low latitudes is most prominent around September equinox, while the WN1/WN2 patterns at middle latitudes are most prominent during local summer in the Southern/Northern hemispheres. Therefore, observations from the late summer season have been selected for low-latitude research, and December/June solstice data have been selected for the southern/northern middle latitudes. To cover the $24 \mathrm{~h}$ local time, 131 and 161 days observations are needed for CHAMP and GRACE, respectively. It should be noticed that for the late summer season the 131/161 days centered on 15 August are selected because WN4 patterns at low latitude are most prominent during this period of time. Hereafter we will term this season September equinox. Days with planetary geomagnetic activity index (Kp) exceeding 3 are not included, to reduce the influence of magnetic disturbances. For each selected period we sort the electron density data into geomagnetic latitude $\left(1^{\circ}\right) \times$ geographic longitude $\left(15^{\circ}\right) \times$ local time $(1 \mathrm{~h})$ bins. For low latitudes, 5 to $20^{\circ}$ MLAT are selected to focus on the crest region of the Equatorial Ionization Anomaly (EIA). For middle latitudes, 40 to $60^{\circ}$ MLAT are selected. For the selected latitude bins, the longitudinal mean values have been subtracted hour by hour, in order to suppress the migrating tides. The longitudinal mean-free data is labeled $\Delta \mathrm{Ne}$ in the present study. For the next step these longitudinal mean-free data are further processed by the onedimensional Fourier transform which will bring forth the sum of observed tidal signatures for each wave number up to 4. A similar approach for obtaining the amplitudes and phases of various tidal signatures for the $\mathrm{F}$ region electron density can be found in Xiong and Lühr (2014). Based on the aforementioned approach the amplitudes of all interesting tidal components can be derived for each period, and their amplitudes will be further used for analyzing the solar activity dependence.

\section{Results}

Figure 1 shows the zonal (longitudinally averaged) mean electron density observed by CHAMP and GRACE satellites between $\pm 70^{\circ}$ MLAT from 2000 to 2014 . The blank areas are missing data. The orbital height at ascending node, as well as the solar radio flux index P10.7 are also presented in the upper panels. The P10.7 is defined as $\mathrm{P} 10.7=(\mathrm{F} 10.7+\mathrm{F} 10.7 \mathrm{~A}) / 2$, where $\mathrm{F} 10.7 \mathrm{~A}$ is the 81 days averaged value of F10.7. We can see that the solar maximum of the solar cycle occurred around 2000-2002, with P10.7 exceeding $250 \mathrm{sfu}$. Then the solar activity gradually decreases, and the solar minimum appears around 2008-2009, with P10.7 below $70 \mathrm{sfu}$. The recovery of solar activity appears around 2010, to the end of 2014 the P10.7 reaches occasionally $200 \mathrm{sfu}$. During their mission periods CHAMP has decayed from $450 \mathrm{~km}$ to about $300 \mathrm{~km}$, and GRACE decayed from $500 \mathrm{~km}$ to about $400 \mathrm{~km}$. The zonal mean electron densities from both satellites show a clear dependence on the solar activity. Take CHAMP for example, the maximum electron density exceeds $1.4 \times 10^{6} \mathrm{~cm}^{-3}$ around 2002 , while the maximum value has decreased roughly to $6 \times 10^{5} \mathrm{~cm}^{-3}$ during 2008-2009 in spite of the orbital decay. The seasonal variation of the $\mathrm{F}$ region electron density can also be found. It maximizes around equinox seasons and minimizes around June solstice. For the latitude variation, the EIA crests gen- 

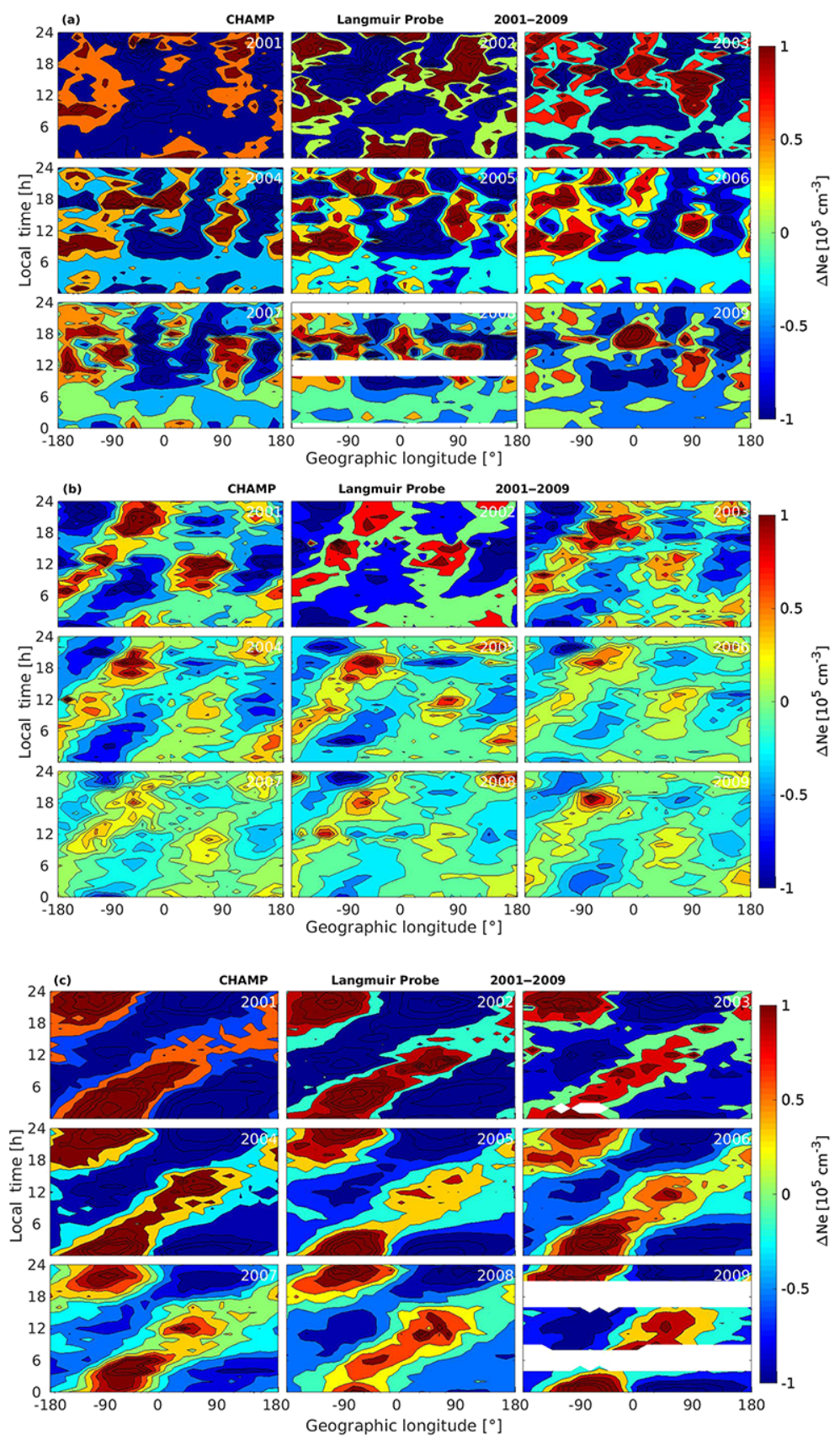

Figure 2. Local time vs. longitudinal distribution of $\Delta N e$ variations observed by CHAMP at low latitudes (a, September equinox), northern middle latitudes (b, June solstice), and southern middle latitudes (c, December solstice) from 2001 to 2009.

erally appear between \pm 8 and $20^{\circ}$ MLat, which is somewhat closer to the magnetic equator during solar minimum years. It is noteworthy that the obvious increase of GRACE electron density during 2014 in fact is additionally reinforced by its orbit decay.

For illustrating the longitudinal wave patterns, taking CHAMP as an example, Fig. 2 presents the local time vs. longitudinal distribution of $\Delta \mathrm{Ne}$ at low latitudes (top panel, September equinox), northern middle latitudes (mid- dle panel, June solstice), and southern middle latitudes (bottom, December solstice) from 2001 to 2009 . Here $\Delta N e$ means the longitudinal mean value of electron density has been subtracted hour by hour. We can clearly see that $\Delta N e$ shows longitudinal WN4, WN2/WN1 patterns at low and middle latitudes, respectively. These robust wave features can be found throughout the CHAMP mission period with somewhat larger amplitudes during higher solar activity years. When looking at the local time variations of these 

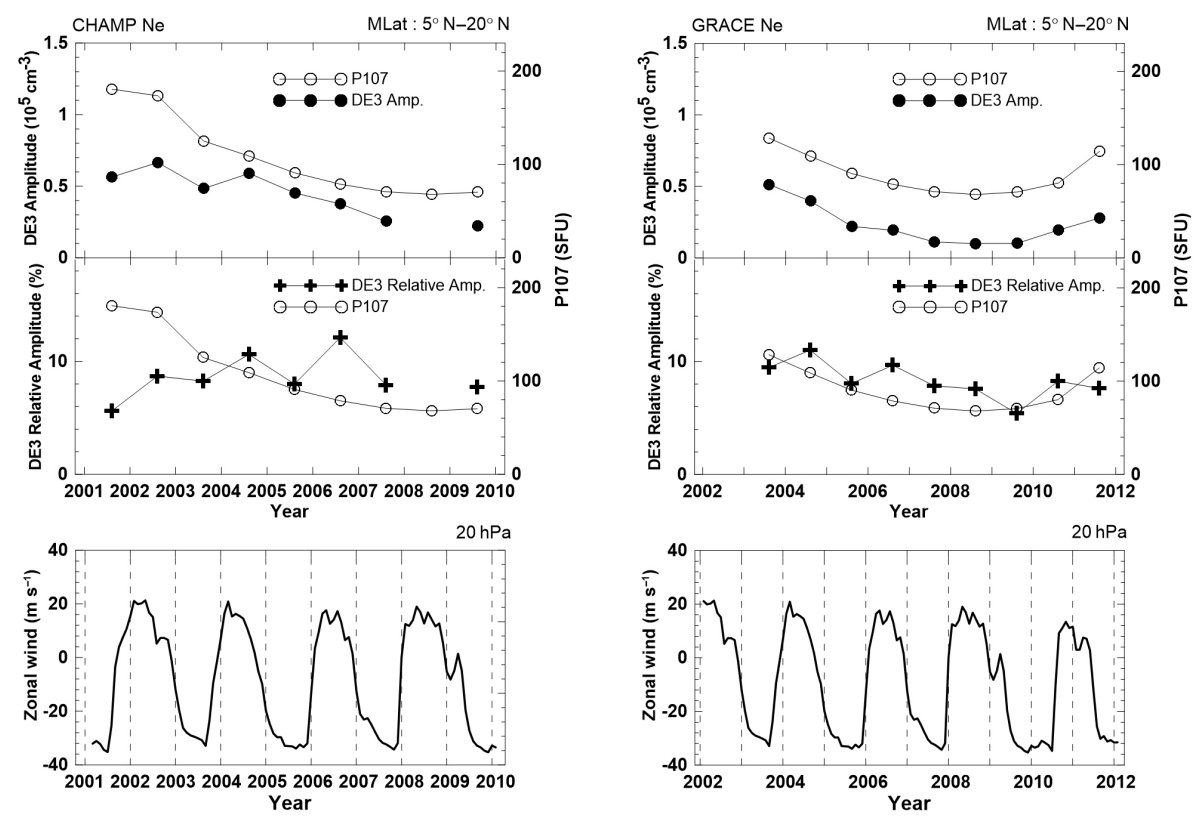

Figure 3. Temporal variation of absolute (top) and relative (middle) amplitudes of the DE3 tidal component observed by CHAMP (left) and GRACE (right) for September equinox at the northern EIA crest region, as well as averaged values of P10.7 solar radio flux for the corresponding same time period. (bottom) Monthly mean of stratospheric $(20 \mathrm{hPa})$ zonal wind at equatorial latitudes.

wave features the WN4 pattern at low latitudes is found to be prominent only during daytime. At low and equatorial latitudes most of the tides are generated in the lower atmosphere and propagate to the upper atmosphere through the $\mathrm{E}$ region wind dynamo coupling mechanism. Therefore the fountain effect is prominent only during daytime. At middle latitudes $\Delta \mathrm{Ne}$ is mostly positive in the southern hemisphere between 30 and $150^{\circ} \mathrm{W}$ around 22:00 LT, while in the Northern Hemisphere two peaks of $\Delta \mathrm{Ne}$ can be found between $90-150^{\circ} \mathrm{W}$ and $30-90^{\circ} \mathrm{E}$ during 12:00-22:00 LT. These longitudes with higher electron density during summer night corresponds well with the mid-latitude summer night anomaly (MSNA), as reported by previous studies (e.g. Lin et al., 2010; Liu et al., 2010). The longitudinal patterns at low and middle latitudes from GRACE observations are similar to that of CHAMP, but are not shown here.

By the aforementioned method we obtained the amplitudes and phases of different tidal components that contribute to the longitudinal structures. It is found that the longitudinal WN4 structures of $\Delta N e$ at low latitude are dominated by the nonmigrating tide DE3, and the contributions from the other components (such as SPW4, DW5, SE2, SW6, TE1 and TW7) are somewhat less important. For the middle latitudes the longitudinal WN1 and WN2 patterns in the Southern and Northern Hemisphere are dominated by the nonmigrating tides D0, DW2, and DE1. Thus in the following we only focus on these four tidal components, to reveal their variation with the solar activity.

We first studied DE3 at low latitudes. Figure 3 presents the temporal variation of the absolute (top) and relative (middle) amplitudes of DE3 components observed by CHAMP (left) and GRACE (right) for September equinox at the northern EIA crest region. For deriving the relative DE3 amplitudes, $\Delta N e$ is first normalized by the zonal mean value hour by hour, then decomposed with the same approach described above. The mean values of P10.7 during the corresponding study period are also presented. The absolute amplitude of DE3 observed by CHAMP is gradually decreasing towards lower solar activity, with smallest amplitudes appearing in 2009 when the level of solar activity reaches a minimum. The absence of a point for 2008 is due to the partly lacking observations. Different from the absolute amplitudes the relative amplitudes of DE3 show little dependence on solar activity. However, the amplitudes in 2002, 2004 and 2006 are somewhat larger than the previous years. At the GRACE altitude the absolute amplitudes of DE3 from GRACE observations are also directly correlated with the solar activity. It gradually decreases with the P10.7 from 2002 to 2009 and then increases again. Similar to the CHAMP observation in 2008, the interrupted observations of GRACE from 2012 to 2014 cannot provide the $24 \mathrm{~h}$ coverage during September equinox (see the blanks in Fig. 1c and d). Therefore, the DE3 amplitudes are not obtained for these years. The relative amplitudes again show little dependence on the solar activity. However, except for the amplitude of DE3 in 2008, larger relative amplitudes during even years appear again. In fact, this 2-year oscillation in the DE3 tides has earlier been reported by Forbes et al. (2008) for migrating tides. They found a prominent quasi-biennial oscillation (QBO) related interannual variation in the temperature at $100 \mathrm{~km}$. It is known that 

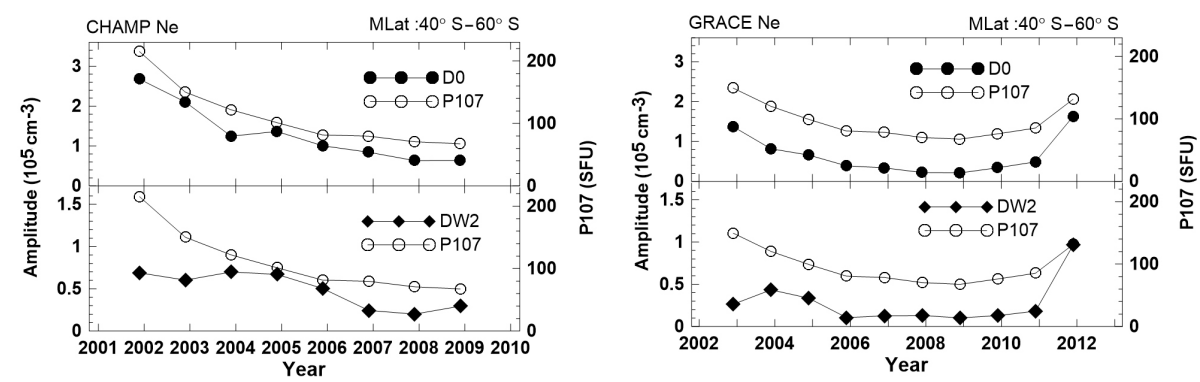

Figure 4. Temporal variation of absolute amplitudes of D0 and DW2 components observed by CHAMP (left) and GRACE (right) for local summer at Southern Hemisphere middle latitudes, as well as averaged values of P10.7 solar radio flux for the corresponding period of time.
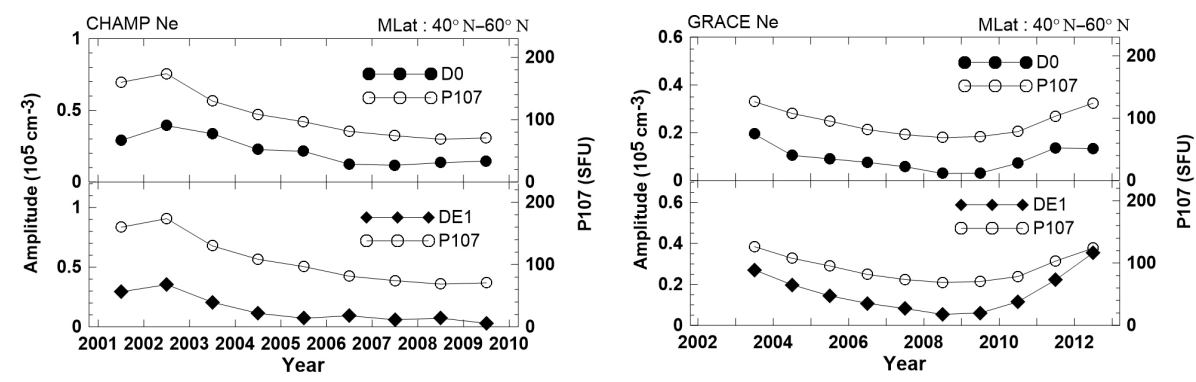

Figure 5. The same as Fig. 4, but for D0 and DE1 tidal components at local summer in the Northern Hemisphere.

QBO dominates the variability of the equatorial stratosphere, and it is easily seen as a downward propagating easterly or westerly wind regime, with a variable period of about 27 months (Baldwin et al., 2001). For comparison, the temporal variation of the observed equatorial stratospheric monthly mean zonal wind at level $20 \mathrm{hPa}$ is added as the third panel in Fig. 3. The positive values of wind velocity mean westerly. It is shown that the relative amplitude of DE3 is larger when the zonal wind in the stratosphere is westerly and is smaller when the zonal wind is easterly. A clear QBO effect can be found in the relative amplitudes of DE3 from both satellites observation. We will come back to this point in the discussion part.

Figure 4 shows the temporal variation of the absolute amplitudes of D0 and DW2 components at southern middle latitudes during local summer. It is clear that the absolute amplitudes of the D0 and DW2 components, which contributed to the prominent WN1 patterns, are closely correlated with the variation of P10.7, especially in case of D0. Figure 5 shows the temporal variation of absolute amplitudes of D0 and DE1 components, which contribute to WN2 patterns at northern middle latitudes during local summer. It can be seen that maximum amplitudes of DE1 and D0 at CHAMP altitude emerge in 2002 with a value of about $0.4 \times 10^{5} \mathrm{~cm}^{-3}$. Clearly, DE1 and D0 have the same trend of variation with the solar activity. As presented in the right panel of Figs. 4 and 5, the absolute amplitudes of the three tides from GRACE observations show similar solar activity dependence as that from CHAMP.
Figure 6 shows the relative amplitudes of D0 and DW2 at southern middle latitudes during local summer from both satellites observations. Figure 7 is the same as Fig. 6, but for DE1 and D0 at northern middle latitudes local summer. No clear dependence on solar activity can be found, and at Southern Hemisphere the relative amplitudes are varying around 48 and $18 \%$ for the D0 and DW2 tides, respectively. For Northern Hemisphere, the amplitudes are about 10 and $16 \%$ for the D0 and DE1 components, respectively.

\section{Discussion}

The analysis presented above has provided the solar activity dependence of the nonmigrating tides in $\mathrm{F}$ region electron density at both low and middle latitudes. Within this section we will discuss our results in the context of previous results related to nonmigrating tides in the ionospherethermosphere system.

\subsection{Nonmigrating tides at low latitudes}

During the past decade lots of previous studies focused on the longitudinal patterns of various ionospheric and thermospheric quantities at the equatorial region. The related tidal components and the possible coupling mechanisms between the mesosphere and lower thermosphere (MLT) and the upper atmosphere have also been proposed (e. g. Sagawa et al., 2005; Immel et al. 2006; England et al., 2006, 2010; Lühr et al., 2008, 2012; Xiong and Lühr, 2013). These tides are usually excited by thermal sources, stationary planetary wave- 

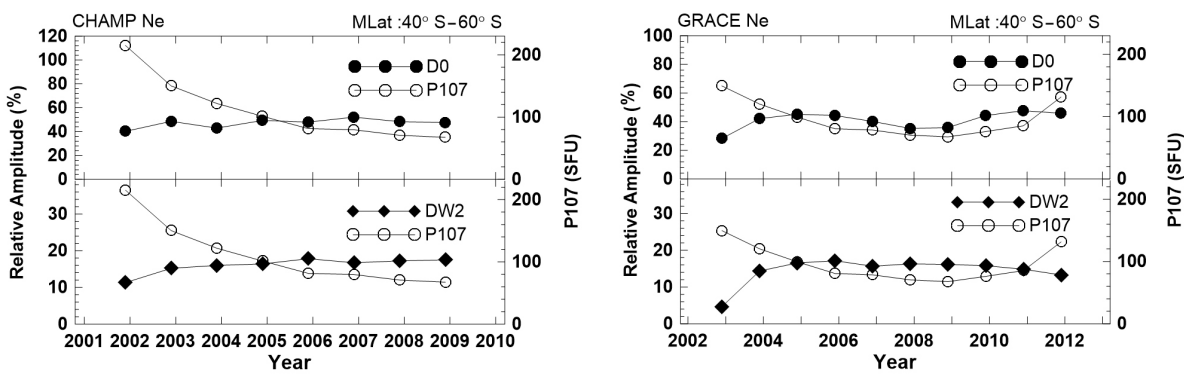

Figure 6. The same as Fig. 4, but for relative amplitudes of D0 and DW2.
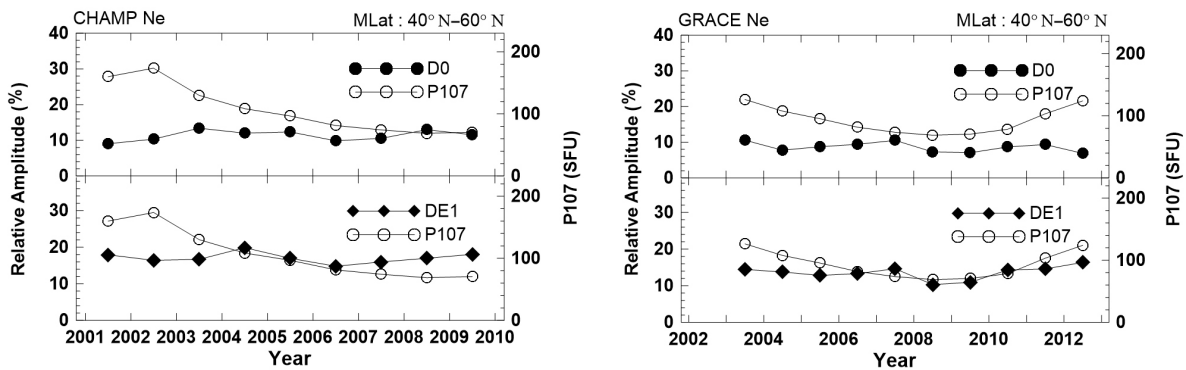

Figure 7. The same as Fig. 5, but for relative amplitudes of D0 and DE1.

tide (e.g., Angelats i Coll and Forbes, 2002) and tide-tide interactions (Hagan et al., 2009; Oberheide et al., 2011). They further propagate upward to the upper atmosphere either by direct propagation (Häusler and Lühr, 2009) or through the $\mathrm{E}$ region wind dynamo coupling mechanism (e.g. Wu et al., 2012).

At daytime the E region zonal electric field transports the plasma upward, thereby depleting the equatorial $\mathrm{F}$ region at the equator and accumulating plasma in the EIA crest regions. The modulation of the $\mathrm{E}$ layer electric field is mapped with a certain time delay into the $\mathrm{F}$ region EIA (Stolle et al., 2008). An interesting feature in our Fig. 2a is that the WN4 longitudinal pattern in electron density at the crests of EIA is quite prominent during daytime hours but vanishes at post-midnight hours. During higher solar activity years (2001-2004), the WN4 pattern at the EIA crest region can also be found between 18:00 and 21:00 LT. This could be explained by the pre-reversal enhancement (PRE), which is defined as a sharp increase in vertical ion drift after sunset via an enhancement of the eastward electric field strength in the F region (e.g., Woodman, 1970; Fesen et al., 2000). The increased $\boldsymbol{E} \times \boldsymbol{B}$ drift will cause an electron density trough above the dip equator. While during solar minimum, the PRE effect is low, therefore, the WN4 patterns in the EIA crest region are not so clear, especially during the years 2008-2009. It could be considered as an indication that when the $\mathrm{E}$ layer disappears during nighttime, other mechanisms for interaction between ions and neutrals may appear in the $\mathrm{F}$ region.

\subsection{Nonmigrating tides at middle latitudes}

Different from the WN4 at low latitudes, WN1/WN2 patterns at middle latitudes show little local time difference between solar maximum and minimum years, except for a reduced magnitude. It implies that at middle latitudes the wave patterns in the $\mathrm{F}$ region may be less related to the $\mathrm{E}$ region. Jones Jr. et al. (2013) suggested that at middle latitudes the nonmigrating tides including DE1, D0, and DW2 could be generated in situ through ion-neutral interactions due to the longitude-dependent ionospheric properties imposed by the geomagnetic field configuration. Similar WN1 patterns in thermospheric mass density and zonal wind are also found at the southern middle latitudes, and the most prominent tidal components are D0 and DW2 (e.g. Xiong et al., 2015b). One interesting feature of D0 is that it shows an anti-phase diurnal variation between hemispheres both in the $\mathrm{F}$ region electron density as well as in the thermospheric mass density and zonal wind (Xiong et al., 2015b). By employing the global ionosphere-thermosphere model (GITM) simulation, $\mathrm{H}$. Wang et al. (2015) found that the thermospheric zonal wind plays an important role in causing the WN1/WN2 patterns of the $\mathrm{F}$ region electron density at middle latitudes, but additional contributions are needed to explain the full extension of observed tides.

\subsection{Solar activity dependence of the nonmigrating tides}

The $\mathrm{F}$ region background electron density is largely controlled by the solar activity, especially the extreme ultraviolet (EUV) radiation. That is why the absolute amplitudes of 
the $\mathrm{F}$ region nonmigrating tides are directly related to P10.7 at both low and middle latitudes, as shown in Figs. 3-5. This is in accord with the result of Chang et al. (2013). By analyzing the TEC observations from the FORMOSAT-3/COSMIC during 2007-2011 they reported that the absolute amplitudes of all the tides contributing to WN4 (DE3, SE2 and SPW4) are directly related to the level of solar activity. Similar results have been reported by S. Wang et al. (2015), based on 14 years (1999-2013) of TEC observations from the global ionospheric maps of JPL. They also found that the absolute amplitudes of DE3 and SPW4 exhibit a saturation effect on the solar activity. This apparent saturation of nonmigrating tidal amplitudes could be explained by the saturation of the TEC values at high solar activity (Liu et al., 2009). In our in situ $\mathrm{Ne}$ observations no saturation effect has been found for the absolute DE3 amplitudes.

When looking at the relative amplitudes of these tides at low latitudes, S. Wang et al. (2015) found little dependence on solar activity, while Chang et al. (2013) claimed that relative amplitudes of WN4 are inversely related to solar activity through 2010. From their Fig. 5a we can see that at $15^{\circ} \mathrm{N}$ the relative amplitudes of DE3 show little variations from 2007 to 2011, and the peak values are around $7 \%$ during the 5 -year period. Compared to the solar maximum from 2001 to 2003, the solar activity during 2007-2011 in fact is rather low, therefore it may not be sufficient from their data to conclude that relative amplitudes of DE3 are inversely related to solar activity. The relatively larger amplitude of DE3 in 2008 (as shown in their Fig. 4a) in our eyes is more reasonably explained by the modulation of the propagation conditions from the troposphere and stratosphere by QBO. Additionally, the relatively small amplitude of DE3 in 2010 may also be related to QBO. It can be seen from our Fig. 3 that the transition time of wind from easterly to westerly during 2009 to 2010 is longer than during previous cycles. Forbes et al. (2008) found a QBO variation of order $\pm 10-15 \%$ in the migrating diurnal and semidiurnal tidal amplitudes in temperature measurements obtained by the SABER instrument on board TIMED between 100 and $116 \mathrm{~km}$. Similar QBO variations in the DE3 tide amplitude have also been reported by Oberheide et al. (2009), from the zonal wind observations at $105 \mathrm{~km}$. The QBO effect described above is mainly found in the E region observations. As shown in our Fig. 3, when normalized by the zonal mean values the QBO effect in the DE3 amplitudes can also be found in the $\mathrm{F}$ region electron density, especially during 2001 to 2007 . The relatively larger amplitudes of the relative DE3, during the periods of westerly stratospheric mean zonal winds are consistent with the results as reported by Forbes et al. (2008) and Oberheide et al. (2009). The similarity of QBO effects found in both $\mathrm{E}$ and $\mathrm{F}$ regions also supports the inference that the low latitude DE3 nonmigrating tides at all levels are driven from below.

At middle latitudes, the absolute amplitudes of the nonmigrating tides are also highly related to the solar activity. However, the QBO effect cannot be found in their relative amplitudes, which implies that the nonmigrating tides in the $\mathrm{F}$ region are not strongly coupled to $\mathrm{E}$ region dynamics at these latitudes.

\section{Summary}

In this study we have used more than 10 years of $\mathrm{F}$ region electron density observations from CHAMP and GRACE to analyze the solar activity dependence of nonmigrating tides at low and middle latitudes. The main results are summarized as follows.

The longitudinal WN4 pattern during September equinox at low latitudes and the WN1/WN2 patterns during local summer at the southern/northern middle latitudes in the F region electron density are robust features throughout the 23/24 solar cycles.

The absolute amplitudes of DE3 at low latitudes as well as DE1, D0 and DW2 at middle latitudes are highly related to the solar activity, all show larger amplitudes during solar maximum years. While their relative amplitudes (normalized by the zonal mean electron density) show little dependence on solar activity.

At low latitudes, a clear modulation by the QBO can be found in the relative amplitudes of DE3 both from CHAMP and GRACE observations, which is consistent with the QBO effect as reported for $\mathrm{E}$ region quantities. It also supports the strong coupling of the nonmigrating tides between the $\mathrm{E}$ and F region. However, no QBO effect can be found in the tidal components DE1, D0 and DW2 at middle altitudes, which implies that these tides are generated in situ at $\mathrm{F}$ region altitudes.

\section{Data availability}

The CHAMP and GRACE data are available at the Information System and Data Center (ISDC) of GFZ German Research Centre for Geosciences. Data set names are as follows: CH-ME-2-PLP, GA-OG-1B-NAVSOL, GB-OG1B-NAVSOL, and GX-OG-1B-KBRDAT. The solar radio flux F10.7 data can be found at http://omniweb.gsfc.nasa. gov/form/dx1.html (OMNIweb, 2015). The Quasi-BiennialOscillation (QBO) data is downloaded from http://www.geo. fu-berlin.de/en/met/ag/strat/produkte/qbo/ (QBO, 2015).

Acknowledgements. The CHAMP and GRACE missions were sponsored by the Space Agency of the German Aerospace Center (DLR) through funds of the Federal Ministry of Economics and Technology. This study is supported by the National Nature Science Foundation of China (No. 41274194) and the Ocean Public Welfare Scientific Research Project, SOA of China (201005017). The work of Yun-Liang Zhou is supported by China Scholarship Council (No. 201506275011).

The topical editor, S. Milan, thanks two anonymous referees for help in evaluating this paper. 


\section{References}

Angelats i Coll, M. and Forbes, J. M.: Nonlinear interactions in the upper atmosphere: The $s=1$ and $s=3$ nonmigrating semidiurnal tides, J. Geophys. Res., 107, SIA 3-1-SIA 3-15, doi:10.1029/2001JA900179, 2002.

Baldwin, M. P., Gray, L. J., Dunkerton, T. J., Hamilton, K., Haynes, P. H., Randel, W. J., Holton, J. R., Alexander, M. J., Hirota, I., Horinouchi, T., Jones, D. B. A., Kinnersley, J. S., Marquardt, C., Sato, K., and Takahashi, M.: The Quasi-Biennial Oscillation, Rev. Geophys., 39, 179-229, 2001.

Chang, L. C., Lin, C.-H., Yue, J., Liu, J.-Y., and Lin, J.-T.: Stationary planetary wave and nonmigrating tidal signatures in ionospheric wave 3 and wave 4 variations in 2007-2011 FORMOSAT-3/COSMIC observations, J. Geophys. Res.-Space, 118, 6651-6665, doi:10.1002/jgra.50583, 2013.

Chen, C. H., Lin, C. H., Chang, L. C., Huba, J. D., Lin, J. T., Saito, A., and Liu, J. Y.: Thermospheric tidal effects on the ionospheric midlatitude summer nighttime anomaly using SAMI3 and TIEGCM, J. Geophys. Res.-Space, 118, 3836-3845, doi:10.1002/jgra.50340, 2013.

England, S. L., Maus, S., Immel, T. J., and Mende, S. B.: Longitudinal variation of the $\mathrm{E}$ region electric fields caused by atmospheric tides, Geophys. Res. Lett., 33, L21105, doi:10.1029/2006GL027465, 2006.

England, S. L., Immel, T. J., Huba, J. D., Hagan, M. E., Maute, A., and DeMajistre, R.: Modeling of multiple effects of atmospheric tides on the ionosphere: An examination of possible coupling mechanisms responsible for the longitudinal structure of the equatorial ionosphere, J. Geophys. Res., 115, A05308, doi:10.1029/2009JA014894, 2010.

Fesen, C. G., Crowley, G., Roble, R. G., Richmond, A. D., and Fejer, B. G.: Simulation of the pre-reversal enhancement in the low latitude vertical ion drifts, Geophys. Res. Lett., 27, 1851-1854, doi:10.1029/2000GL000061, 2000.

Forbes, J. M.: Tidal and PlanetaryWaves, in: The upper Mesosphere and Lower Thermosphere: A Review of Experiment and Theory, Geophysical Monograph, 87, edited by: Johnson, R. M. and Killeen, T. L., AGU, 1995.

Forbes, J. M., Zhang, X., Ward, W., and Talaat, E.: Nonmigrating diurnal tides in the thermosphere, J. Geophys. Res., 108, 1033, doi:10.1029/2002JA009262, 2003.

Forbes, J. M., Russell, J., Miyahara, S., Zhang, X., Palo, S., Mlynczak, M., Mertens, C. J., and Hagan, M. E.: Tropospherethermosphere tidal coupling as measured by the SABER instrument on TIMED during July-September 2002, J. Geophys. Res., 111, A10S06, doi:10.1029/2005JA011492, 2006.

Forbes, J. M., Zhang, X., Palo, S., Russell, J., Mertens, C. J., and Mlynczak, M.: Tidal variability in the ionospheric dynamo region, J. Geophys. Res., 113, A02310, doi:10.1029/2007JA012737, 2008

Hagan, M. E. and Forbes, J. M.: Migrating and nonmigrating diurnal tides in the middle and upper atmosphere excited by tropospheric latent heat release, J. Geophys. Res., 107, 4754, doi:10.1029/2001JD001236, 2002.

Hagan, M. E. and Roble, R. G.: Modeling the diurnal tidal variability with the National Center for Atmospheric Research thermosphere-ionosphere-mesosphere-electrodynamics general circulation model, J. Geophys. Res., 106, 24869-24882, doi:10.1029/2001JA000057, 2001.
Hagan, M. E., Maute, A., and Roble, R. G.: Tropospheric tidal effects on the middle and upper atmosphere, J. Geophys. Res., 114, A01302, doi:10.1029/2008JA013637, 2009.

Häusler, K. and Lühr, H.: Nonmigrating tidal signals in the upper thermospheric zonal wind at equatorial latitudes as observed by CHAMP, Ann. Geophys., 27, 2643-2652, doi:10.5194/angeo27-2643-2009, 2009.

Immel, T. J., Sagawa, E., England, S. L., Henderson, S. B., Hagan, M. E., Mende, S. B., Frey, H. U., Swenson, C. M., and Paxton, L. J.: Control of equatorial ionospheric morphology by atmospheric tides, Geophys. Res. Lett., 33, L15108, doi:10.1029/2006GL026161, 2006.

ISDC: Information System and Data Center of GFZ German Research Center for Geoscience, available at: http://isdc. gfz-potsdam.de/modules.php?name=product_type_overview, 2015.

Jones Jr., M., Forbes, J. M., Hagan, M. E., and Maute, A.: Nonmigrating tides in the ionosphere-thermosphere: In situ versus tropospheric sources, J. Geophys. Res.-Space, 118, 2438-2451, doi:10.1002/jgra.50257, 2013.

Kil, H., Oh, S.-J., Kelley, M. C., Paxton, L. J., England, S. L., Talaat, E., Min, K.-W., and Su, S.-Y. : Longitudinal structure of the vertical $E \times B$ drift and ion density seen from ROCSAT-1, Geophys. Res. Lett., 34, L14110, doi:10.1029/2007GL030018, 2007.

Lin, C. H., Liu, C. H., Liu, J. Y., Chen, C. H., Burns, A. G., and Wang, W.: Midlatitude summer nighttime anomaly of the ionospheric electron density observed by FORMOSAT-3/COSMIC, J. Geophys. Res., 115, A03308, doi:10.1029/2009JA014084, 2010.

Liu, H., Yamamoto, M., and Lühr, H.: Wave-4 pattern of the equatorial mass density anomaly: A thermospheric signature of tropical deep convection, Geophys. Res. Lett., 36, L18104, doi:10.1029/2009GL039865, 2009.

Liu, H., Thampi, S. V., and Yamamoto, M.: Phase reversal of the diurnal cycle in the midlatitude ionosphere, J. Geophys. Res. 115, A01305, doi:10.1029/2009JA014689, 2010.

Liu, L., Wan, W., Ning, B., and Zhang, M.: Climatology of the mean total electron content derived from GPS global ionospheric maps, J. Geophys. Res., 114, A06308, doi:10.1029/2009JA014244, 2009.

Lühr, H. and Xiong, C.: IRI-2007 model overestimates electron density during the 23/24 solar minimum, Geophys. Res. Lett., 37, L23101, doi:10.1029/2010GL045430, 2010.

Lühr, H., Rother, M., Häusler, K., Alken, P., and Maus, S.: The influence of nonmigrating tides on the longitudinal variation of the equatorial electrojet, Geophys. Res. Lett., 113, A08313, doi:10.1029/2008JA013064, 2008.

Lühr, H., Rother, M., Häusler, K., Fejer, B., and Alken, P.: Direct comparison of non-migrating tidal signatures in the electrojet, vertical plasma drift and equatorial ionization anomaly, J. Atmos. Sol.-Terr. Phy., 7576, 3143, doi:10.1016/j.jastp.2011.07.009, 2012.

McLandress, C. and Ward, W. E.: Tidal/gravity wave interactions and their influence on the large-scale dynamics of the middle atmosphere: Model results, J. Geophys. Res., 99, 8139-8155, doi:10.1029/94JD00486, 1994.

McNamara, L., Cooke, D. L., Valladares, C. E., and Reinisch, B. W.: Comparison of CHAMP and Digisonde plasma 
frequencies at Jicamarca, Peru, Radio Sci., 42, RS2005, doi:10.1029/2006RS003491, 2007.

Oberheide, J., Hagan, M. E., Roble, R. G., and Offermann D.: Sources of nonmigrating tides in the tropical middle atmosphere, J. Geophys. Res., 107, 4567, doi:10.1029/2002JD002220, 2002.

Oberheide, J., Forbes, J. M., Häusler, K., Wu, Q., and Bruinsma, S. L.: Tropospheric tides from $80-400 \mathrm{~km}$ : propagation, interannual variability and solar cycle effects, J. Geophys. Res., 114, D00I05, doi:10.1029/2009JD012388, 2009.

Oberheide, J., Forbes, J. M., Zhang, X., and Bruinsma, S. L.: Wave-driven variability in the ionosphere-thermospheremesosphere system from TIMED observations: What contributes to the "wave 4"?, J. Geophys. Res., 116, A01306, doi:10.1029/2010JA015911, 2011.

OMNIweb: Interface to produce plots, listings or ouput files from OMNI 2, available at: http://omniweb.gsfc.nasa.gov/form/dx1. html, 2015.

QBO: Department of Earth science/Institute of meteorology, available at: www.geo.fu-berlin.de/en/met/ag/strat/produkte/qbo/, 2015.

Reigber, C., Lühr, H., and Schwintzer, P.: CHAMP mission status, Adv. Space Res., 30, 129-134, 2002.

Sagawa, E., Immel, T. J., Frey, H. U., and Mende, S. B.: Longitudinal structure of the equatorial anomaly in the nighttime ionosphere observed by IMAGE/FUV, J. Geophys. Res., 110, A11302, doi:10.1029/2004JA010848, 2005.

Schunk, R. W. and Sojka, J. J. : Ionosphere-thermosphere space weather issues, J. Atmos. Sol.-Terr. Phy., 58, 1527-1574, doi:10.1016/0021-9169(96)00029-3, 1996.

Stolle, C., Manoj, C., Lühr, H., Maus, S., and Alken, P.: Estimating the daytime equatorial ionization anomaly strength from electric field proxies, J. Geophys. Res., 113, A09310, doi:10.1029/2007JA012781, 2008.

Tapley, B. D., Bettadpur, S., Watkins, M., and Reigber, C.: The gravity recovery and climate experiment: Mission overview and earlyresults, Geophys. Res. Lett., 31, L09607, doi:10.1029/2004GL019920, 2004.

Wang, H., Ridley, A. J., and Zhu, J.: Theoretical study of zonal differences of electron density at midlatitudes with GITM simulation, J. Geophys. Res.-Space, 120, 2951-2966, doi:10.1002/2014JA020790, 2015.
Wang, S., Huang S., and Fang, H.: Wave- 3 and wave 4 patterns in the low and mid latitude ionospheric TEC, J. Atmos. Sol.-Terr. Phy., 132, 82-91, 2015.

Woodman, R. F.: Vertical drift velocities and east-west electric fields at the magnetic equator, J. Geophys. Res., 75, 6249-6259, doi:10.1029/JA075i031p06249, 1970.

Wu, Q., Ortland, D. A., Foster, B., and Roble, R. G.: Simulation of nonmigrating tide influences on the thermosphere and ionosphere with a TIMED data driven TIEGCM, J. Atmos. Sol.-Terr. Phy., 90-91, 61-67, doi:10.1016/j.jastp.2012.02.009, 2012.

Xiong, C. and Lühr, H.: Nonmigrating tidal signatures in the magnitude and the inter-hemispheric asymmetry of the equatorial ionization anomaly, Ann. Geophys., 31, 1115-1130, doi:10.5194/angeo-31-1115-2013, 2013.

Xiong, C. and Lühr, H.: The Mid-latitude Summer Night Anomaly as observed by CHAMP and GRACE: Interpreted as tidal features, J. Geophys. Res., 119, 4905-4915, doi:10.1002/2014JA019959, 2014.

Xiong, C., Park, J., Lühr, H., Stolle, C., and Ma, S. Y.: Comparing plasma bubble occurrence rates at CHAMP and GRACE altitudes during high and low solar activity, Ann. Geophys., 28, 1647-1658, doi:10.5194/angeo-28-1647-2010, 2010.

Xiong, C., Lühr, H., and Stolle, C.: Seasonal and latitudinal variations of the electron density nonmigrating tidal spectrum in the topside ionospheric $\mathrm{F}$ region as resolved from CHAMP observations, J. Geophys. Res., 119, 10416-10425, doi:10.1002/2014JA020354, 2014.

Xiong, C., Lühr, H., Ma, S., and Schlegel, K.: Validation of GRACE electron densities by incoherent scatter radar data and estimation of plasma scale height in the topside ionosphere, Adv. Space Res., 55, 2048-2057, doi:10.1016/j.asr.2014.07.022, 2015a.

Xiong, C., Zhou, Y.-L., Lühr, H., and Ma, S.-Y.: Tidal signatures of the thermospheric mass density and zonal wind at midlatitude: CHAMP and GRACE observations, Ann. Geophys., 33, 185196, doi:10.5194/angeo-33-185-2015, 2015b.

Zhang, Y., England, S., and Paxton, L. J.: Thermospheric composition variations due to nonmigrationg tides and their effect on ionosphere, Geophys. Res. Lett., 37, L17103, doi:10.1029/2010GL044313, 2010. 